\title{
The Importance of Social Sustainability in Digital Transformation: A New Definition Proposal
}

\author{
Dilek Kurt (Corresponding author) \\ Turkish-German University, Istanbul, Turkey \\ E-mail: dilek.kurt@tau.edu.tr \\ Fatma Sena Karal \\ Turkish-German University, Istanbul, Turkey \\ E-mail: karal@tau.edu.tr
}

\begin{abstract}
Social effects caused by digital transformation technologies are spreading to all areas of life with new technological developments. Digital transformation fundamentally changes people's habits and determines the life style and quality of future generations. With the emergence of the digital society, social sustainability gains a special importance in digital transformation. The fact that the Industry 5.0 vision of the EU Commission is focused on sustainability and people along with flexibility emphasizes the increasing importance of social sustainability in the digital age.

The positive connection of digital transformation with social sustainability is clearly expressed in scientific studies. However, despite this positive relationship and the increasing importance, it is seen that social sustainability is not included in the digital transformation definitions in the literature. This study, based on literature research, provides a new definition by examining the social sustainability dimension of digital transformation within the scope of sustainability. The proposed new definition emphasizes the importance of the social sustainability dimension together with the strategic dimension of digital transformation.
\end{abstract}

Keywords: Digital Transformation, Social Sustainability, Digital Strategies, Industry 5.0

DOI: $10.7176 / J S T R / 7-02-04$

\section{Dijital Dönüşümde Sosyal Sürdürülebilirliğin Önemi: Yeni Tanım Önerisi}

\section{Özet}

Dijital dönüşüm teknolojilerinin neden olduğu sosyal etkiler yeni teknolojik gelişmeler ile birlikte yaşamın her alanına yaygınlaşmaktadır. Dijital dönüşüm insanların alışkanlıklarını temelden değiştirmekte, gelecek nesillerin yaşam tarzını ve kalitesini belirlemektedir. Dijital toplumun oluşmaya başlaması ile birlikte sosyal sürdürülebilirlik dijital dönüşümde ayrı bir önem kazanmaktadır. AB Komisyonu'nun Endüstri 5.0 vizyonunun da esneklik ile birlikte sürdürülebilirliğe ve insana odaklı olması sosyal sürdürülebilirliğin dijital çağda artan önemini vurgulamaktadır.

Dijital dönüşümün sosyal sürdürülebilirlik ile olumlu bağlantısı bilimsel çalışmalarda da açık bir şekilde ifade edilmektedir. Ancak bu olumlu ilişkiye ve sosyal sürdürülebilirliğin artan önemine rağmen literatürdeki dijital dönüşüm tanımlarında sosyal sürdürülebilirliğe yer verilmediği görülmektedir. Literatür araştırmasına dayanan bu bilimsel çalışma, dijital dönüşümün sürdürülebilirlik kapsamında sosyal sürdürülebilirlik boyutunu inceleyerek literatüre yeni bir tanım kazandırmaktadır. Önerilen yeni tanım, dijital dönüşümün stratejik boyutu ile birlikte sosyal sürdürülebilirlik boyutunun önemini vurgulamaktadır.

Anahtar Kelimeler: Dijital Dönüşüm, Sosyal Sürdürülebilirlik, Dijital Stratejiler, Endüstri 5.0

28 | P a g e

www.iiste.org 


\section{Giriş}

Toplumların dönüşümü yaşanan devrimler ile birlikte gerçekleşmektedir. Neolitik devrim yerleşik toplumu, sanayi devrimi ise sanayi toplumunu yaratmış, içinde bulunduğumuz dijital devrim dijital toplumu oluşturmaya başlamıştır. Dijital toplum henüz başlangıç aşamasında bulunmasına rağmen, dijital dönüşüm ile birlikte insanların öğrenme ve iletişim kurma yöntemleri, birlikte yaşama ve birlikte çalışma alışkanlıkları temelden değişmeye başlamıştır. Dijitalleşme hızla artarken teknolojiyi insan hayatının bir parçası olarak görmek, yeni ortaya çıkan sosyal ihtiyaçlara cevap vermek ve teknolojiye güven duymak bu süreçte daha çok önemli hale gelmiştir. $\mathrm{Bu}$ nedenle dijital dönüşümün insanı merkezine alarak sosyal boyutu göz önünde bulunduran sürdürülebilir yönetimi işletmelerin gelecekteki varoluşları için stratejik önem taşımaktadır.

Avrupa Birliği Komisyonu da Ocak 2021'de açıklamış olduğu "Industry 5.0: Towards a sustainable, human-centric and resilient European industry” başlıklı Endüstri 5.0 vizyonuyla esneklik ile birlikte insana ve sürdürülebilirliğe odaklanmaktadır. AB Komisyonu bu vizyonuyla Avrupa'da esnek bir sanayi hedefi ile birlikte iki önemli kavramı odak noktası olarak görmektedir: sürdürülebilirlik ve insan. AB Komisyonu böylece beşinci sanayi devriminin kilit konularını net bir şekilde ön plana çıkarmaktadır (European Commission, 2021).

Sürdürülebilirlik kavramı ilk kez 1987 yılında BM Dünya Çevre ve Kalkınma Komisyonu (WCED) tarafından hazırlanan "Ortak Geleceğimiz" başlıklı Brundtland Raporunda sürdürülebilir kalkınma ekseninde ele alınmış ve sürdürülebilir kalkınma "gelecek nesillerin kendi ihtiyaçlarını karşılama yeteneğinden ödün vermeden bugünün ihtiyaçlarını karşılama” (World Commission on Environment and Development [WCED], 1987:40) şeklinde tanımlanmıştır. Sürdürülebilirlik, işletmelerin temel amaçları olan ekonomik büyümenin yanında; çevrenin korunumu ile birlikte sosyal gelişimi dikkate almalarını içermektedir (aktaran Margherita ve Braccini, 2020).

2015 yılında Birleşmiş Milletler'in Kalkınma Ajansı (UNDP) tarafından 17 Sürdürülebilir Kalkınma Amacı (SKA), diğer bir deyişle Küresel Amaçlar açıklanmıştır. 2030 sürdürülebilirlik gündemini destekleyen SKA'lar gelecek nesiller için yaşamı sürdürülebilir biçimde iyileştirmeyi, bugünden doğru seçimleri yapacak şekilde ortaklık ve pragmatizm ruhuyla yürütülmesini hedef almaktadır (“Sürdürülebilir Kalkınma Amaçları Nelerdir?”, t.y.). SKA'ların altısı sosyal konulara odaklanan sürdürülebilir kalkınma amaçlarına yöneliktir.

Artarak kullanılan dijital dönüşüm teknolojileri insanların tüketimi, eğitimi, katılımı, güvenliği, sağlığı ve hareketliliği gibi farklı sosyal alanları etkilemektedir. Dijital teknolojilerin insanların yaşamına farklı sosyal etkilerde bulunduğu literatürde çeşitli yazarlar tarafından ifade edilmektedir (Ghobakhloo, 2020; Margherita ve Braccini, 2020; Faludi, 2020; Gregori ve Holzmann, 2020; Fenwick ve Edwards, 2016). Günlük hayatımızın önemli bir parçası haline gelen dijital inovasyonlar aynı anda gelecek nesillerin yaşam tarzını ve kalitesini de belirlemektedir (Osburg, 2017). Gelişen dijital teknolojilerin yaşamın her alanına yaygınlaşması ve etkisini artırması da kaçınılmazdır. Tüketicinin sürdürülebilirlik kavramına olan ilgisinin sürekli bir şekilde arttı̆̆ı da bilinmektedir (Junge ve Straube, 2020). Dolayısıyla tüketicinin bu konudaki bilinçlenmesinin sosyal sürdürülebilirliğe olan beklentisini de artırması kaçınılmaz olacaktır.

Dijital dönüşüm sosyal sürdürülebilirlik ile olumlu bağlantısı olan bir değişim sürecidir (aktaran Anania ve Passani, 2014; Fenwick ve Edwards, 2016; aktaran Cangiano, Romano ve Loglio, 2017; Faludi, 2020; Ghobakhloo, 2020). Ancak bu olumlu ilişkiye ve sosyal sürdürülebilirliğin artan önemine rağmen güncel literatürdeki dijital dönüşüm tanımlarında sosyal sürdürülebilirliğe yer verilmediği görülmektedir.

Kapsamlı literatür çalışmasına dayanan bu araştırmanın amacı, dijital dönüşümün sosyal sürdürülebilirlik boyutu ile birlikte stratejik boyutunu kapsayan, literatüre katkıda bulunacak yeni bir tanım önermektir. Önerilen dijital dönüşüm tanımını açıklamak üzere sürdürülebilirlik kapsamında sosyal sürdürülebilirlik ile birincil literatürde yer alan dijital dönüşüm tanımları incelenmiş ve dijital dönüşüm ile sosyal sürdürülebilirlik ilişkisi araştırılmıştır.

\section{Sosyal Sürdürülebilirlik Boyutu}

AB Komisyonu'nun Ocak 2021'de yayınlamış olduğu Endüstri 5.0 vizyonunun esneklik dışında sürdürülebilirliğe ve insana odaklılığa dayanması sosyal sürdürülebilirliğin dijital çağda artan önemini

29 | P a g e

www.iiste.org 
ve Avrupa'daki sanayinin bu alanlardaki gelecek hedefini vurgulamaktadır (European Commission, 2021). Bu nedenle sosyal sürdürülebilirlik kavramından önce $A B$ Komisyonu'nun yeni vizyonunun ve sürdürülebilirlik kavramının açıklanmasında yarar görülmektedir.

\subsection{AB Komisyonu'nun Endüstri 5.0 Vizyonu: Sürdürülebilir, İnsan Odaklı, Esnek}

Ocak 2021'de yayınlamış olduğu Endüstri 5.0 vizyonu ile AB Komisyonu araştırma ve inovasyon sayesinde mevcut "Endüstri 4.0" paradigmasını tamamlayarak sürdürülebilir, insan merkezli ve esnek bir Avrupa endüstrisine geçişi sağlamayı hedeflemektedir. AB Komisyonu (2021), Endüstri 4.0'ın gündemde olduğu on yıldan fazla bir süre boyunca üretimdeki verimliliği ve esnekliği artırmak için sosyal adaletin orijinal prensiplerine ve sürdürülebilirliğe daha az, dijitalizasyona ve yapay zeka odaklı teknolojiye ise daha çok odaklandığını söylemektedir.

Endüstri 5.0 vizyonuyla $\mathrm{AB}$ Komisyonu farklı bir bakış açısı sağlamakta ve araştırma ile inovasyonun endüstrinin gezegen sınırları içinde insanlığa uzun vadeli hizmet sunmasındaki önemini vurgulamaktadır. AB Komisyonu'na göre gerçek refahın sağlayıcısı olması için sanayinin temel amacı sosyal, çevresel ve toplumsal hususları içermek olmalıdır. Bu, yalnızca veya öncelikli olarak maliyet etkinliğini artırmayı veya kârı maksimize etmeyi değil, aynı zamanda dâhil olan herkes için yatırımcılar, iş̧̧iler, tüketiciler, toplum ve çevre- refahı artırmayı amaçlayan sorumlu inovasyonu içermelidir. $\mathrm{AB}$ Komisyonu'na göre inovasyon, "blue-sky" araştırmalar (mavi gökyüzü araştırmaları) ve sosyal evrim tarafından tetiklenmektedir. Böylece yeni çözümler araştırılarak ve uygulanarak yeni ortaya çıkan sosyal ihtiyaçlara uyum sağlanmaktadır.

AB Komisyonu Endüstri 5.0'ı şu şekilde tanımlamaktadır (European Commission, 2021: 14):

"Endüstri 5.0, üretimi gezegenimizin sinırlarına saygıll hale getirerek ve endüstri çalı̧sanlarının refahın üretim sürecinin merkezine yerleştirerek endüstrinin, işlerin ve büyümenin ötesinde, toplumsal hedeflere ulaşma ve dayanıkl bir refah sağlayıcı olma gücüne vurgu yapmaktadır."

Beşinci sanayi devrimi vizyonundaki "sürdürülebilir, insan odaklı ve esnek" olma yaklaşımı temelinde insana hizmet etmektedir. Üç temel unsurun açıklamalarına bakıldığında bu hizmet anlayışı daha net görülmektedir (European Commission, 2021):

- $\mathrm{AB}$ Komisyonu'nun raporunda, sürdürülebilirlik hedefi ile gezegenin sınırlarına saygı duyması için endüstrinin sürdürülebilir olması gerektiği belirtilmektedir. Çevrenin korunması ile gelecek nesillerin ihtiyaçlarının tehlikeye atılmadan günümüz kuşaklarının ihtiyaçlarının karşılanması gerektiği vurgulanmaktadır. Yapay zekâ ve katmanlı üretim gibi teknolojilerin kaynak verimliliğini optimize ederek ve israfı en aza indirerek burada büyük bir rol oynayabileceği belirtilmektedir.

- İnsan-odaklı yaklaşım ise endüstride temel insan ihtiyaçlarını ve çıkarlarını üretim sürecinin merkezine koymaktadır. Teknolojinin insanlar için neler yapabileceğine odaklanılmakta, teknoloji sayesinde üretim sürecinin işçinin ihtiyaçlarına uyarlanması istenmekte (örneğin; yönlendirmek ve eğitmek) ve yeni teknoloji kullanımının işçilerin mahremiyet hakkı, özerklik ve insan onuru gibi temel haklarını etkilememesinin garanti altına alınması hedeflenmektedir. $\mathrm{Bu}$ yaklaşım ile teknoloji odaklı ilerlemeden tamamen insan merkezli bir yaklaşıma doğru kaymanın olduğu vurgulanmaktadır. Bu, endüstrinin kimseyi geride bırakmamayı amaçlayarak toplumsal kısıtlamaları dikkate alması gerektiği anlamına gelmektedir. Güvenli ve faydalı bir çalışma ortamı hedefi ile insan merkeze alınmaktadır.

- Endüstri 5.0'daki esneklik ise endüstriyel üretimde daha yüksek derecede sağlamlık geliştirme, onu kesintilere karşı daha iyi teçhizatlandırma ve kriz zamanlarında kritik altyapıyı sağlayıp destekleyebilme ihtiyacını ifade etmektedir. Yeterince dayanıklı stratejik değer zincirleri, uyarlanabilir üretim kapasitesi ve dayanıklı iş süreçleri geliştirilerek, değer zincirlerinin özellikle sağlık veya güvenlik gibi temel insan ihtiyaçlarına hizmet ettiği yerlerde dengelenmesi gerektiği belirtilmektedir.

AB Komisyonu Endüstri 5.0 konseptini, Avrupa endüstrisinin gelecekteki işbirlikçi ve ortak yaratıcı vizyonunun daha fazla gelişimine altyapı sağlayan, açık ve gelişen bir konsept olarak görmektedir. 


\subsection{Sürdürülebilirlik}

Sürdürülebilirlik kavramı ilk olarak Birleşmiş Milletler vasıtasıyla ortaya çıkmıştır (aktaran Giovannoni ve Fabietti, 2013). Kavram 1970'li ylllara kadar ormancillk sektöründe, orman kaynaklarının kullanım biçimi konusunda bilgi vermek amacıyla kullanılmışır (Holzbaur, 2020; Kuhlman ve Farrington, 2010; Leal Filho, 2000). Sürdürülebilirlik kavramı aynı zamanda "uzun vadeli" ve "dayanıklı" gibi birçok farklı kelimeyle aynı anlama gelecek şekilde kullanılmıştır (Leal Filho, 2000). Fakat kavramın tam olarak kabul edilmesi ve tanınması Brundtland Raporu sayesinde olmuştur (Kuhlman ve Farrington, 2010).

Alıntılanma sayısı oldukça fazla olan Brundtland Raporu'nda (WCED, 1987) sürdürülebilirlik kavramı "gelecek nesillerin kendi ihtiyaçların karşılama yeteneğinden ödün vermeden bugünün ihtiyaçlarını karşılama" olarak tanımlanmıştır. Fakat çalışmaların geneline bakıldığında, kavramın tanımı konusunda fikir birliğinin söz konusu olmadığ görülmektedir. Yapılan tanımların bazılarında insan yaşamına vurgu yapılırken, bazılarında ise gelecek kavramı ön plana çıkarılmaktadır. Kavramın seçilen tanımı, kuruluşların politik bakış açıları ve hedefleri doğrultusunda değişiklik göstermektedir (Leal Filho, 2000).

Sürdürülebilirlik kavramı birden fazla boyutu barındırmaktadır. 1994 yılında John Elkington, 3P'den oluşan (planet, people, profit) "triple bottom line" (TBL) terimini ortaya koyarak işletmenin sosyal, çevresel ve ekonomik etkisini sorgulayan bir sürdürülebilirlik çerçevesi oluşturmuştur. Elkington TBL'i iş liderlerinin kapitalizmi yeniden düşünmesi için bir meydan okuma olarak görmüştür. Böylece işletmelerin sadece kâra odaklanmayı bırakıp, insanların yaşamlarını ve gezegenin sağlığını iyileştirmeyi içerecek şekilde odaklarını genişletmeyi öğreneceklerini varsaymıştır. Ancak Elkington 25 yıl sonra TBL'in sadece bir muhasebe aracı olarak değerlendirilmiş olmasını eleştirmiş; sürdürülebilirlik hedeflerindeki başarı ya da başarısızlı̆̆ın yalnızca kar ve zarar açısından ölçülemeyeceğini, ayrıca milyarlarca insanın refahı ve gezegenimizin sağlığı açısından da ölçülmesi gerektiğini savunmuştur (Elkington, 2018).

Sürdürülebilirliğin üç ana bileşenden meydana geldiği görüşü kabul gören ve birçok çalışmada baz alınan bir görüștür. Fakat bu üçlü modelde farklılık yapılması gerektiğini savunan çalışmalara da rastlanılmaktadır. Bu tarz çalışmalara Kuhlman ve Farrington'ın (2010) çalışmasını örnek göstermek mümkündür. Kuhlman ve Farrington, refah ve sürdürülebilirlik olmak üzere iki bileşen tanımlamakta; refah bileşeninin sosyal ve ekonomik bileşenlere, sürdürülebilirlik bileşeninin ise çevre bileşenine karşı1lk geleceğini söylemektedir.

Sürdürülebilirlik genel olarak değerlendirildiğinde çevre boyutu ön planda tutulmaktadır (aktaran Giovannoni ve Fabietti, 2013). İnsanın çevre üzerindeki olumsuz etkisi incelenmekte, bu etkinin azaltılması için yöntemler tanımlanmaktadır (Bañon Gomis, Guillén Parra ve Hoffman, 2011). Yönetim ve işletme perspektifinden bakıldığında ise durum oldukça farklılık göstermektedir. $\mathrm{Bu}$ perspektife göre sürdürülebilirlik ve yeşil kavramları bir tarafta stratejilerin vazgeçilmezi olarak görülürken, diğer tarafta desteklenmesi sadece kâr veya stratejik avantaj benzeri kavramlara dayandırılmaktadır (Bañon Gomis vd., 2011). Fakat bu görüşe, sürdürülebilirlik kavramının sadece maddi kazanca dayandırılamayacağını, konunun doğal kaynakların korunumu olduğunu söyleyerek karşı çıkanlar da bulunmaktadır (aktaran Kuhlman ve Farrington, 2010). Bañon Gomis vd. (2011) ise konuya farklı bir boyut katmakta, sürdürülebilirliğe etik vurgusunu da eklemektedir.

BM Dünya Çevre ve Kalkınma Komisyonu, ekonomik ve sosyal sistemler ve ekolojik koşullar ülkeler arasında büyük farklılıklar gösterdiğinden, tek bir sürdürülebilirlik planının bulunamayacağını söylemiștir. Her ulusun, kendi somut politika sonuçlarını değerlendirmek zorunda kalacağını, buna rağmen bu farklılıklardan bağımsız olarak, sürdürülebilir kalkınmanın küresel bir hedef olarak görülmesi gerektiğini savunmuştur (WCED, 1987). Sürdürülebilir kalkınma, sosyal sorumluluğu ve küresel öğrenmeyi içermektedir (Holzbaur, 2020).

2015 yılında Birleşmiş Milletler'in Kalkınma Ajansı (UNDP) tarafından 17 Sürdürülebilir Kalkınma Amacı (SKA), diğer bir deyişle Küresel Amaçlar açıklanmıştır. SKA'lar şu şekilde tanımlanmıştır: "Küresel Amaçlar, yoksulluğu ortadan kaldırmak, gezegenimizi korumak ve tüm insanların barış ve refah içinde yaşamasını sağlamak için evrensel eylem çağrısıdır." "Sürdürülebilir Kalkınma Amaçları Nelerdir?", t.y.). 2030 sürdürülebilirlik gündemini destekleyen SKA'lar, gelecek nesiller için yaşamı sürdürülebilir biçimde iyileştirmek için bugünden doğru seçimleri yapacak şekilde ortaklık ve pragmatizm ruhuyla hareket edilmesini hedef almaktadır.

31 I P a g e www.iiste.org 


\subsection{Sosyal Sürdürülebilirlik}

Sosyal sürdürülebilirlik, adil iş uygulamaları sonucunda toplumun yarar göreceği değerlerin yaratılması (Margherita ve Braccini, 2020); hem nesil içi hem de nesiller arası eşitliğin sağlanması (Ballet, Bazin ve Mahieu, 2020; Osburg, 2017) ile ilgilenmektedir. Ghobakhloo (2020) sosyal sürdürülebilirliği, "insan üzerindeki olumlu ve olumsuz iş, çevre, ekonomik ve teknolojik etkileri tanıma ve yönetme süreci" olarak tanımlamaktadır. UN Global Compact tarafindan sosyal sürdürülebilirlik 2016 yllında insanlar üzerindeki olumlu ve olumsuz ticari etkilerin belirlenmesi ve yönetilmesi olarak tanımlanmıştır (Osburg ve Lohrmann, 2017).

Sosyal sürdürülebilirlik, insan üzerinde önemli etkileri olan çeşitli büyük sosyal meseleleri ortaya koymakta; bu meselelerle mücadele edilebilmesi için uygulamalar sunmaya çalışmaktadır (Eizenberg ve Jabareen, 2017). Sosyal sürdürülebilirliğin amacı, tüm bireylerinin güvenlik ve sağlık gibi temel haklarına sahip olduğu bir toplum inşa etmektir (aktaran Ghobakhloo, 2020). Bu tanım sosyal sürdürülebilirliğin yaşam kalitesine etkisini de (aktaranlar Ballet vd., 2020; Grum ve Kobal Grum, 2020; Margherita ve Braccini, 2020) destekler niteliktedir.

Sosyo-ekolojik sistemin karmaşık ve değişken yapısı (Missimer, Robèrt ve Broman, 2017a) ve sosyal bilimler alanında yapılan birbirinden farklı çalışmalar, sosyal sürdürülebilirlik kavramının saptanmasında karmaşaya sebep olmaktadır (Vallance, Perkins ve Dixon, 2011). Eizenberg ve Jabareen (2017) sosyal sürdürülebilirlik ile çevresel ve ekonomik sürdürülebilirlik arasındaki bağlantının sağlanamamasının açık bir tanımlama yapılmasını engellediğini, konseptin anlaşılması ve uygulanmasını zorlaştırdığını söylemektedir.

Fakat kavramın çok tanımlı yapısının sorun teşkil etmediğini, kavramın karmaşık yapısının zaten bunu imkânsız kıldığını savunan araştırmalar da bulunmaktadır (aktaran Missimer, Robèrt ve Broman, 2017b). BM Dünya Çevre ve Kalkınma Komisyonu'nun, ekonomik ve sosyal sistemlerin ve ekolojik koşulların ülkeler arasında büyük farklılıklar göstermesi nedeniyle tek bir sürdürülebilirlik planının bulunmayacağını belirtmiş olması da (1987) sosyal sürdürülebilirlik ile ilgili tek bir tanımın olmamasını destekler niteliktedir.

Toplumu meydana getiren insanlar kendi ihtiyaçlarını karşılamak için sosyal ve ekolojik sistemlere bağlıdır (Missimer vd., 2017a). Aynı yazarlara göre insanları barındıran sosyal sistemler sadece karmaşı değil, aynı anda karmaşık uyarlanabilir sistemlerdir. Karmaşık uyarlanabilir sistemler kaçınılmaz olarak belirsizlik, değişim ve sürpriz ile karakterize edilmekte, bu da sistemle uğraşırken esneklik ve uyarlama gerektirmektedir. Bu görüş sosyal sürdürülebilirlik kavramının tek bir tanım ile sınırlı kalamayacağının da bir göstergesidir.

Sosyal sürdürülebilirlik üzerine yapılan diğer çalışmalarda da birçok farklı kavrama dikkat çekildiği görülmektedir. Eizenberg ve Jabareen (2017) iklim değişikliği ve çevresel tehlikelerin sebep olacağı riske ve güvenliğe; Ballet vd. (2020) kuşak içi ve kuşaklar arası eşitliğe vurgu yapmakta; Grum ve Kobal Grum (2020)'ın incelediği birçok çalışmada yaşam kalitesi kavramı ön plana çıkmaktadır. Diğer çalışmalara bakıldığında, sosyal sürdürülebilirlik kavramı incelenirken üzerinde durulan kavramları daha da çeşitlendirmek mümkün olmaktadır.

Vallance vd. (2011), sosyal sürdürülebilirliği üçe ayırmaktadır: geliştirme sürdürülebilirliği, köprü sürdürülebilirliği ve koruma sürdürülebilirliği. Geliştirme sürdürülebilirliği, maddi ve maddi olmayan ihtiyaçları; köprü sürdürülebilirliği, insanlar ve çevre arasında kurulan bağlantıları; koruma sürdürülebilirliği ise insanlar tarafından korunması istenen tüm sosyal ve kültürel değerler ile çevrenin korunmasını içermektedir. Missimer vd. (2017b) ise sosyal sürdürülebilir bir toplumun bireylerinin ihtiyaçlarını karşılama konusunda hangi alanlarda engellerle karşılaşmaması gerektiğini sıralamaktadır. Eizenberg ve Jabareen (2017), kaynakların korunumu konusunda teknolojik yeniliklere başvurulduğunu, fakat sosyal kavrama gecikmeli olarak odaklanmaya başlandığını vurgulamaktadır. Sosyal sürdürülebilirlik kavramı önemli olmasına ve bir nevi içinde çevresel sürdürülebilirliği de barındırmasına rağmen (Ballet vd., 2020), üç boyuttan en az gelişen olmuştur (aktaran Missimer vd., 2017a). Dijital dönüşümün sosyal boyutları üzerinde de bugüne kadar yeterince durulmamıştır (Mergel, Edelmann ve Haug, 2019). Beier, Ullrich, Niehoff, Reißig ve Habich (2020)_ise, dijital dönüşümde sürdürülebilir gelişmenin ancak baştan ve açık şekilde tanımlanan hedefler aracılığıyla gerçekleştirilebileceğini ifade etmektedir. 


\section{Dijital Dönüşüm Tanımları}

Dijital dönüşüm ile ilgili gerek literatürde gerekse uygulamada birbirinden farklı tanımlar kullanılmaktadır. Dijital dönüşümün tanımı; odaklanılan sektöre, işletmeye ve ilgili departmana ve bunların ihtiyaçlarına, beklentilerine ve zorluklarına göre değişiklik göstermektedir. $\mathrm{Bu}$ nedenle işletmelerin ihtiyaçları farklı dijital dönüşüm stratejileri ile karşılanmakta, dijital dönüşüm yolculukları farklılık göstermektedir ("Was bedeutet digitale Transformation für Unternehmen?", t.y.). Tekic ve Koroteev (2019) dijital dönüşümü, işletmeler için farklı yönleri ve etkileri olduğu için çok yönlü bir olgu olarak değerlendirmektedir.

$\mathrm{Bu}$ farklılıklar literatürdeki tanımlara da yansımaktadır. Akademik çalışmalarda dijital dönüşüm için resmi bir sınıflandırmanın bulunmaması ve sınırların net çizilmemiş olması bir neden olarak görülmektedir (Reis, Amorim, Melão ve Matos, 2018). Bilimsel çalışmalarda yer alan tanımlar incelendiğinde, dijitalleşmenin "dönüşüm” boyutunun farklı kavramlar ile tanımlandığı, uygulamada kullanılan dijital teknolojilerin farklı etkilerinin olduğu ve dijital dönüşüm ile çeşitli beklentilere odaklanıldığı görülmektedir.

$\mathrm{Bu}$ araştırma kapsamında bilimsel makalelerde kullanılan dijital dönüşüm tanımları incelenmiştir. Bilimsel çalışmaların taramaları yoğun olarak Google Scholar, ScienceDirect, Scopus, JSTOR, Web of Science ve IEEE Xplore üzerinden yapılmıştır. Derleme yapılırken kaynaklardaki tanımların birçoğunda "dijitalleşme" (digitalization), "dijital dönüşüm stratejisi” (digital transformation strategy) ve "dijital işletme stratejisi” (digital business strategy) gibi kavramların tanımlarının da "dijital dönüşüm" tanımı olarak kabul edildiği ve yapılan birçok çalışmaya dâhil edildiği fark edilmiştir. Bu nedenle bu araştırmada sadece "dijital dönüşüm” kavramını tanımlayan bilimsel çalışmaların taraması yapılmıştır. Ayrıca tanımdan ziyade dijital dönüşüm ile ilgili açıklama yapan kaynaklar aşağıdaki tabloda değerlendirilmemiştir.

Dijital dönüşüm tanımını ele alan çalışmalar ayrıntılı bir şekilde incelenmiş, bazılarında yanlış alıntılama yapıldığı fark edilmiştir. O nedenle çalışmalarda yer alan tüm tanımlar - yer aldıkları asıl çalışmalara kadar gidilerek - titiz bir şekilde araştırılmıştır. Türkçe dilinde yayımlanan bilimsel çalışmalarda literatürde yer alan mevcut dijital dönüşüm tanımlarının değerlendirildiği, yeni tanımların ise bulunmadığı tespit edilmiştir. Araştırma kapsamında değerlendirilen tanımlar ve tanımı yapan yazarlar tabloda aktarılmıştır.

Tablo 1. Literatürden derlenen dijital dönüşüm tanımları

\begin{tabular}{|l|l|}
\hline \multicolumn{1}{|c|}{ Yazar } & \multicolumn{1}{c|}{ Tanım } \\
\hline Andriole (2017) & Makul bir şekilde işleyen bir sistem için planlanmış dijital bir şok. \\
\hline $\begin{array}{l}\text { Berghaus ve Back } \\
(2016)\end{array}$ & $\begin{array}{l}\text { Hem verimlilik odaklı süreç dijitalleşmesini hem de mevcut fiziksel } \\
\text { ürünleri dijital yeteneklerle geliştirmeye odaklanan dijital inovasyonu } \\
\text { kapsar. }\end{array}$ \\
\hline Bloching vd. (2015) & $\begin{array}{l}\text { Tüm ekonomik sektörlerin uçtan uca ağ oluşturması ve paydaşların } \\
\text { dijital ekonominin yeni koşullarına adaptasyonu. }\end{array}$ \\
\hline $\begin{array}{l}\text { Demirkan, Spohrer ve } \\
\text { Welser (2016) }\end{array}$ & $\begin{array}{l}\text { Dijital teknolojilerin getirdiği değişim ve firsatlardan ve bunların } \\
\text { toplumdaki etkisinden stratejik ve öncelikli bir şekilde tam olarak } \\
\text { yararlanmak için iş faaliyetlerinin, süreçlerinin, yetkinliklerinin ve } \\
\text { modellerinin köklü ve ivmeli dönüşümü. }\end{array}$ \\
\hline $\begin{array}{l}\text { Fitzgerald, Kruschwitz, } \\
\text { Bonnet ve Welch } \\
\text { (2013) }\end{array}$ & $\begin{array}{l}\text { Önemli iş iyileştirmelerini (müşteri deneyimini geliştirmek, } \\
\text { operasyonları düzene koymak veya yeni iş modelleri oluşturmak gibi) } \\
\text { sağlamak için yeni dijital teknolojilerin (sosyal medya, mobil, analitik } \\
\text { veya gömülü cihazlar) kullanımı. }\end{array}$ \\
\hline $\begin{array}{l}\text { Gimpel ve Röglinger } \\
(2015)\end{array}$ & $\begin{array}{l}\text { Sürdürülebilir değer yaratımını sağlamak için, ilerleyen dijitalleşme } \\
\text { 1şı̆ğnda şirketlerin adaptasyon yönetimi. }\end{array}$ \\
\hline $\begin{array}{l}\text { Müşterilerle etkileşim ve bağlantı kurmanın yeni yollarını sağlayan satış } \\
\text { ve iletişim kanallarının dijitalleştirilmesi ve bir firmanın tekliflerinin } \\
\text { (ürünler ve hizmetler) fiziksel tekliflerin yerini alan veya artıran } \\
\text { dijitalleştirilmesi. }\end{array}$ \\
\hline Benlian (2016)
\end{tabular}

33 | P a g e

www.iiste.org 


\begin{tabular}{|c|c|}
\hline Hartl ve Hess (2017) & $\begin{array}{l}\text { Kuruluşlardaki ürünlerin, hizmetlerin, temel süreçlerin, müşteri temas } \\
\text { noktalarının ve iş modellerinin dijitalleştirilmesi yoluyla gerçekleşen BT } \\
\text { destekli değişim. }\end{array}$ \\
\hline $\begin{array}{l}\text { Heilig, Schwarze ve } \\
\text { Voss (2017) }\end{array}$ & $\begin{array}{l}\text { Yeni imkanlar sunan BT/BS çözümleri ve trendleri tarafindan } \\
\text { yönlendirilen kuruluşlarda gerçekleşen dönüşümler. }\end{array}$ \\
\hline $\begin{array}{l}\text { Henriette, Feki ve } \\
\text { Boughzala (2016) }\end{array}$ & $\begin{array}{l}\text { Sosyal bir fenomen veya kültürel evrim ve şirketler için bir iş modelinin } \\
\text { evrimi veya oluşturulması. }\end{array}$ \\
\hline $\begin{array}{l}\text { Hess, Benlian, Matt ve } \\
\text { Wiesböck (2016) }\end{array}$ & $\begin{array}{l}\text { Ürünlerin veya organizasyonel yapıların veya süreçlerin otomasyonuna } \\
\text { neden olan, dijital teknolojilerin bir şirketin iş modelinde meydana } \\
\text { getirdiği değişimler. }\end{array}$ \\
\hline i-scoop (t.y.) & $\begin{array}{l}\text { Dijital teknolojilerin, süreçlerin ve yetkinliklerin tüm seviyelerde ve } \\
\text { işlevlerde aşamalı ve stratejik bir şekilde akıllıca entegrasyonu yoluyla } \\
\text { bir örgütün, endüstrinin veya ekosistemin kültürel, örgütsel ve işlevsel } \\
\text { değişimi. }\end{array}$ \\
\hline Kane (2017) & $\begin{array}{l}\text { Kuruluşun giderek dijitalleşen bir dünyada etkili bir şekilde rekabet } \\
\text { etmesine yardımcı olmak için iş süreçleri ve uygulamaları benimsemek. }\end{array}$ \\
\hline KPMG (2020) & $\begin{array}{l}\text { Müşteri odaklı bir işletim modeli tasarlamak ve uygulamak için en son } \\
\text { teknolojileri kullanan yeni bir iş dönüşümü paradigması. }\end{array}$ \\
\hline $\begin{array}{l}\mathrm{Li}, \mathrm{Su}, \text { Zhang ve Mao } \\
(2018)\end{array}$ & $\begin{array}{l}\text { BT'ye yer vermek ve uyarlamak için BT'nin örgütsel yapı, rutinler, bilgi } \\
\text { akışı ve örgütsel yetkinlikler üzerindeki etkisini vurgular. }\end{array}$ \\
\hline $\begin{array}{l}\text { Liu, Chen ve } \\
\text { Chou(2011) }\end{array}$ & Dijital teknolojilerin iş süreçlerine entegrasyonu. \\
\hline Mazzone (2014) & $\begin{array}{l}\text { Bir şirketin, iş modelinin, fikrin, sürecin veya metodolojinin hem } \\
\text { stratejik hem de taktiksel olarak tedbirli ve süregiden dijital evrimi. }\end{array}$ \\
\hline Mergel vd. (2019) & $\begin{array}{l}\text { Geleneksel dijitalleştirme çabalarının ötesinde, hükümetin temel } \\
\text { süreçlerini ve hizmetlerini revize etmek için bütüncül bir çaba. }\end{array}$ \\
\hline $\begin{array}{l}\text { Morakanyane vd. } \\
(2017)\end{array}$ & $\begin{array}{l}\text { İş modelleri, operasyonel süreçler ve müşteri deneyimlerinin değer } \\
\text { yaratması için dijital yetkinlikleri ve teknolojileri kullanan evrimsel bir } \\
\text { süreç. }\end{array}$ \\
\hline $\begin{array}{l}\text { Nwankpa ve Roumani } \\
(2016)\end{array}$ & $\begin{array}{l}\text { Büyük veri, analitik, bulut, mobil ve sosyal medya platformlarına } \\
\text { yapılan örgütsel bir geçiş. }\end{array}$ \\
\hline PwC (2015) & $\begin{array}{l}\text { Kurumsal dünyada yeni teknolojilerin yerleştirilmesi yoluyla köklü bir } \\
\text { değişim. }\end{array}$ \\
\hline $\begin{array}{l}\text { Schuchmann ve Seufert } \\
(2015)\end{array}$ & $\begin{array}{l}\text { Müşteri deneyimi yaşam döngüsündeki her temas noktasında dijital } \\
\text { müşterilerle daha etkili bir bağ kurmak için teknoloji ve yeni iş } \\
\text { modellerinin yeniden düzenlenmesi. }\end{array}$ \\
\hline $\begin{array}{l}\text { Stief, Eidhoff ve Voeth } \\
\text { (2016) }\end{array}$ & $\begin{array}{l}\text { Teknolojik gelişmelerden yeni firsatlar ve büyüme potansiyeli elde } \\
\text { etmek için şirketin mevcut iş faaliyetlerine, geliştirilmiş veya tamamen } \\
\text { yeni süreç, ürün ve iş modellerine yol açan bilgi ve iletişim } \\
\text { teknolojilerinin uygulanması. }\end{array}$ \\
\hline Solis (2017) & $\begin{array}{l}\text { Sürekli gelişen dijital ekonomide iş ve rekabeti geliştirmek, müşteriler } \\
\text { ve çalışanlara yeni ve uygun değer sunmak için yeni teknoloji, zihniyet, } \\
\text { iş ve operasyonel modellere yatırım yapmak ve onları geliştirmek. }\end{array}$ \\
\hline $\begin{array}{l}\text { Stolterman ve Fors } \\
(2004)\end{array}$ & $\begin{array}{l}\text { Dijital teknolojinin insan hayatının her alanında neden olduğu veya } \\
\text { etkilediği değişimler. }\end{array}$ \\
\hline Unruh ve Kiron (2017) & $\begin{array}{l}\text { Dijital yayılma yoluyla gerçekleşen ekonomilerin, kurumların ve } \\
\text { toplumun } \\
\text { sistem düzeyinde yeniden yapılandırılması. }\end{array}$ \\
\hline Vial (2019) & $\begin{array}{l}\text { Dijital teknolojilerin, bu sürecin olumlu ve olumsuz sonuçlarını } \\
\text { etkileyen yapısal değişiklikleri ve örgütsel engelleri yönetirken değer } \\
\text { yaratma yollarını değiştirmeye çalışan kuruluşlarda stratejik tepkileri } \\
\text { tetikleyen aksamalar meydana getiren bir süreç. }\end{array}$ \\
\hline
\end{tabular}




\begin{tabular}{|l|l|}
\hline $\begin{array}{l}\text { Westerman, Calméjane, } \\
\text { Bonnet, Ferraris ve } \\
\text { McAfee (2011) }\end{array}$ & $\begin{array}{l}\text { İşletmelerin performansının veya erişiminin temelinden iyileştirilmesi } \\
\text { için teknolojinin kullanılması. }\end{array}$ \\
\hline Zaoui ve Souissi (2020) & $\begin{array}{l}\text { Şirketler, paydaşları ve müşterileri arasındaki ilişkileri yeniden } \\
\text { tanımlamayı ve şirketler çok boyutlu bir dönüşüm geçirirken hizmet ve } \\
\text { ürün sunmaya yönelik önceki yaklaşımları gözden geçirmeyi gerektiren } \\
\text { yeni bir gelişim modeli. }\end{array}$ \\
\hline
\end{tabular}

Tabloda yer alan tanımlar incelendiğinde, dijitalleşmenin “dönüşüm” boyutunun farklı kavramlar ile tanımlandığı görülmektedir. Dijital dönüşüm, tek seferlik bir eylemden ziyade sürekliliği olan bir süreçtir. Ancak bazı tanımlarda "dönüşüm”ün süreç olgusunu kapsayan ifadeler yerine farklı kavramlar kullanılmaktadır. Aşağıdaki liste bu kavramların çeşitliliğini göstermektedir:

- yeniden uygulama

- yeniden yapılandirma

- yeniden düzenleme

- örgütsel geçiş

- entegrasyon

- yeni koşullara / yeni gerçeklere adaptasyon

- değişim

- gelişim

- örgütsel geçiş

- dijital şok

- dönüşüm

Bazı kaynaklarda ise dönüşümün evre evre gerçekleşen bir değişme süreci olma özelliğini yansıtmak amacıyla dijital dönüşüm "evrimsel bir süreç veya evrim” olarak tanımlanmaktadır. Tanımların ortak noktası, dijital dönüşümün dijital teknolojilerin kullanılması ile gerçekleşmesi ve bunun sonucunda ortaya çıkan etkilerdir. Tanımlara göre, dijital dönüşümde kullanılan dijital teknolojiler;

- yetkinlikleri,

- organizasyonel yapiları,

- $\quad$ iş operasyonlarını,

- iş modellerini,

- müşterileri,

- ürünleri,

- hizmetleri ve

- kültürü

etkilemektedir.

Derlenen tanımlara göre dijital dönüşümün odaklandığı beklentilerin farklı olduğu görülmektedir. Yukarıda da belirtildiği gibi beklentiler; sektörün, işletmenin veya departmanın ihtiyaçlarına bağlı olarak farklılık gösterebilmektedir. Dijital dönüşümden beklentiler şu şekilde sıralanabilir:

- performansın iyileştirilmesi

- $\quad$ erişimin iyileştirilmesi

- değer yaratılması

- dijital yeteneklerin geliştirilmesi

- uçtan uca ağın oluşturulması

- $\quad$ işlerin iyileştirilmesi

- müşteriler ile etkileşimin etkinleştirilmesi

- $\quad$ satış ve iletişim kanallarının, ürünlerin, hizmetlerin, süreçlerin, müşteri temas noktalarının dijitalleştirilmesi

- $\quad$ süreçlerin otomasyonu

- ürünlerin veya organizasyonel yapıların değişimi

35 | P a g e

www.iiste.org 
- $\quad$ iş ve rekabetin geliştirilmesi

- ilişkilerin yeniden tanımlanması

Tanımlarda sosyal konulara ve sürdürülebilirliğe dair arama yapıldığında ise sadece birkaç tanımda şu kavramlarla karşılaşılmaktadır: Sosyal medya (Fitzgerald vd., 2013; Nwankpa ve Roumani, 2016), sosyal fenomen (Henriette vd., 2016), toplumdaki etki (Demirkan vd., 2016), insan hayatı (Stolterman ve Fors, 2004) ve sürdürülebilir değer yaratımı (Gimpel ve Röglinger, 2015).

Dijital dönüşümün sosyal boyutu bazı tanımlarda "toplum", "insan", "müşteri”" ve "sosyal" kavramları ile sınırlı kalmakta, sürdürülebilirlik kavramı ise sadece Gümpel ve Röglinger (2015) tarafindan kaleme alınan "sürdürülebilir değer yaratımı" ifadesinde yer almaktadır. Bu yazarların dışında bu araştırma kapsamında incelenen dijital dönüşüm tanımlarında "sürdürülebilirlik" ve "sosyal sürdürülebilirlik" terimleri ise hiç kullanılmamıştır.

Dijital dönüşümün sosyal boyutu tanımlarda yerini almasa da dijital dönüşümün üçlüsü olarak açıklanan faktörler arasında "insan" ve "sosyal" kavramları yer almaktadır. Disselkamp ve Heinemann (2018); teknoloji, iş ve insan üçgenini tanımlarken, Reis vd. (2018) bu üçlüyü teknolojik, organizasyonel ve sosyal faktörler ile belirlemektedir. Yazarlar bu faktörleri şu şekilde tanımlamaktadır:

- Teknolojik: Yeni teknolojilerin kullanılması.

- Organizasyonel: Organizasyonel süreçlerde bir değişiklik veya yeni iş modellerinin yaratılmas1.

- Sosyal: İnsan yaşamını tüm yönleriyle etkileyen bir olgunun olması.

\section{Dijital Dönüşümün Sosyal Sürdürülebilirlik Boyutu}

Dijital dönüşümün insan hayatını kolaylaştıran ve yaşam kalitesini artıran sosyal etkileri günümüzde fiili olarak kendini göstermektedir. Gelişen dijital teknolojilerin artan kullanımı ile birlikte bu sosyal etkilerinin yaygınlaşmasının daha da mümkün olacağı düşünülmektedir. Osburg ve Lohrmann'a (2017) göre dijital dönüşümün gelecekte yaşam kalitemizi artıracak yeni firsatlara öncülük edeceği açık bir şekilde ortadadır.

Literatürde ve bazı araştırma kurumlarının raporlarında dijital dönüşümden ziyade dijitalleşme ve Endüstri 4.0 ile sürdürülebilirlik ve sosyal sürdürülebilirlik arasındaki ilişki açıklanmaktadır. $\mathrm{AB}$ Komisyonu'nun yeni vizyonu da Endüstri 5.0 ile ilgili sürdürülebilirliğe ve insan boyutuna odaklanmaktadır. Dijitalleşmenin dijital dönüşümün önemli bir parçası ve tetikleyicisi olduğu göz önüne alındığında, dijitalleşmeyi ve gerek dördüncü gerekse beşinci sanayi devrimi ile ilgili söylenenleri dijital dönüşümden bağımsız düşünmek mümkün değildir. Gartner IT Sözlüğüne göre, "dijitalleşme bir iş modelini değiştirmek ve yeni gelir ve değer üreten firsatlar sağlamak için dijital teknolojilerin kullanılması, dijital bir işletmeye geçme sürecidir." ("Digitalization", t.y.). Dijital dönüşüm ise dijitalleşmeden daha geniş bir terimi ve dijitalleşme sürecinin neden olduğu etkiyi oluşturmaktadır (Bloomberg, 2018; Samuels, 2018). Sonuç itibariyle, dijitalleşme dijital dönüşümün bir parçasıdır. Dijitalleşme olmazsa dijital dönüşümün gerçekleşmesi de mümkün değildir.

Uygulamada dijital dönüşüm teknolojilerinin sosyal etkilerinin çok yönlü olduğu örnekler ile açıkça görülmektedir:

- yeni iş imkanları (aktaran Anania ve Passani, 2014; Ghobakhloo, 2020; Margherita ve Braccini, 2020)

- iş içeriklerinde ve ortamında değiş̧me (Fenwick ve Edwards, 2016; Margherita ve Braccini, 2020)

- insan kaynağının eğitimi ve gelişimi (aktaran Anania ve Passani, 2014; Ghobakhloo, 2020; Margherita ve Braccini, 2020)

- güvenlik (Ghobakhloo, 2020)

- $\quad$ sosyal refah (aktaran Cangiano vd., 2017; Faludi, 2020)

- değer yaratma (Faludi, 2020; Gregori ve Holzmann, 2020)

- insanları bir araya getirme, bağlantı kurma (Faludi, 2020; Gregori ve Holzmann, 2020)

- insan davranışlarını etkileme, yönlendirme (aktaran Anania ve Passani, 2014; Faludi, 2020)

- çeşitli sosyal meselelere çözümler getirme (aktaran Cangiano vd., 2017; Faludi, 2020; Fenwick ve Edwards, 2016)

36 | P a g e

www.iiste.org 
Sosyal boyutun incelendiği çalışmalarda, yeni teknolojilerin sağlayacağı faydalara ek olarak sebep olacağı sorunlara odaklananlar da mevcuttur. Gelecekteki iş firsatları ve içerikleri konusunda; insanın mı makinenin mi sorumlu tutulacağı sorusunun cevabında birçok belirsizlik söz konusudur (Beier vd., 2020). Dijitalleşmenin maaş, eşitlik, sağlık ve güvenlik gibi konularda hangi yönde etkilere sebep olacağı bir problem olmaktan çıkamamaktadır (aktaran Guo vd., 2020).

Dijital teknolojilerin topluma olumlu ve olumsuz etkilerini John Naisbitt "High Tech High Touch“ kitabında açıklamıştır. Toplumun derinden ve kalıcı olarak değişmesini megatrend olarak tanımlayan John Naisbitt, 1999 yılında yayınlamış olduğu bu kitabında dijital teknolojilerin toplumun değişimdeki etkilerini incelemiştir. Naisbitt, iyi açıdan bakıldığında teknolojinin insan yaşamını desteklediğini ve geliştirdiğini, kötü açıdan bakıldığında ise insanı yabancılaştırdığını, izole ettiğini, yozlaştırdığını ve yıprattı̆̆ını savunmaktadır (Naisbitt, Naisbitt ve Philips, 1999).

Dijitalleşme ile sürdürülebilirlik konusunu araştıran çalışmalar iki kavram arasındaki bağlantıyı net bir şekilde vurgulamaktadır. $\mathrm{Bu}$ çalışmalar dijitalleşmenin insan yaşamına olumlu etkisini de göstermektedir.

Gregori ve Holzmann (2020) dijitalleşme ile sürdürülebilirlik arasında mantıksal bir bağlantının olduğunu savunmaktadır. Dijital sürdürülebilirliğe yönelik uluslararası alanda çalışmalarını yürüten GeSI tarafından yapılan araştırmaya göre dijital erişim ile UNDP'nin sürdürülebilirlik küresel amaçlarının (SKA) yerine getirilmesi arasında güçlü bir pozitif ilişki bulunmaktadır. Gelişmiş, gelişmekte olan ve az gelişmiş toplam 157 ülkeyi kapsayan araştırma 11 SKA'nın (\%65) dijital erişim ile pozitif ilişkisinin olduğunu ortaya koymaktadır. UNDP'nin SKA'ları arasında sosyal konulara odaklanan SKA'ları "açlığa son” (SKA 2), "sağlık ve kaliteli yaşam” (SKA 3), "nitelikli eğitim” (SKA 4) ve "barış, adalet, güçlü kurumlar" (SKA 16) amaçlarını kapsamaktadır ("A strong and positive link", t.y.).

GeSI'nin dijital erişim indeksi ile SKA'nın indeksi arasındaki korelasyon, sosyal sürdürülebilirlik amaçları (insanların yaşam kalitesinin artırılması) ile ekonomik sürdürülebilirlik amaçlarının (adil büyümenin güçlendirilmesi) en güçlü pozitif ilişkiye sahip olduğunu göstermektedir. GeSI araştırması, dijital teknolojilerin insanların katılımını artırmaya ve herkesin refahını sağlamaya yönelik yeni iş modellerini yaratma hususundaki potansiyelini ortaya koymaktadır.

Dijital gelişmelerin insan yaşamını iyileştirmesi nedeniyle SKA'lara katkıda bulunacağı yönündeki beklentiler de yüksek tutulmaktadır. E-sağlık ile 1,6 milyar insanın daha fazla erişilebilir, uygun fiyatlı ve daha kaliteli tıbbi hizmetlerden yararlanabileceği; bağlantılı araç çözümleri sayesinde yılda 720.000 'e kadar hayatın kurtarılabileceği ve 30 milyona kadar trafik kazasının önlenebileceği savunulmaktadır. Bu tür gelişmelerin SKA'ların 3. Maddesi olan "Sağlık ve Kaliteli Yaşam” amacına ulaşılmasına katkıda bulunacağı belirtilmektedir. Online eğitim sayesinde ise dünyadaki eğitime katkıda bulunularak "Nitelikli Eğitim" amacını taşıyan dördüncü SKA'ya katkıda bulunulabileceği düşünülmektedir (Osburg ve Lohrmann, 2017: xvi, xvii).

Dijitalleşmenin uzun vadeli olarak sürdürülebilir gelişime katkıda bulunması ise dijitalleşmenin nasıl paylaşıldığına bağlı olacaktır. UNDP'nin tahminine göre 2050 yılında dokuz milyar insanın dünyada yaşayacağı düşünüldüğünde, bu büyük demografik değişimin dünyayı derinden etkilemesi kaçınılmazdır. Ancak tüm toplumun sürdürülebilir gelişimi, dünyanın geleceği için çok önemli bir husustur (Osburg ve Lohrmann, 2017: vi).

$\mathrm{AB}$ Komisyonu Endüstri 5.0 vizyonunda, Endüstri 4.0’’n üretimdeki verimliliği ve dayanıklılı̆̆ artırmak için sosyal adalete ve sürdürülebilirliğe daha az, dijitalizasyona ve yapay zeka odaklı teknolojiye ise daha çok odaklandığını söylemektedir (European Commission, 2021). Bu açıklama literatürde de kendini göstermektedir. Endüstri 4.0'ın sosyal boyutu az sayıda bilimsel çalışmada belirtilmektedir. Ghobakhloo (2020), Endüstri 4.0 sayesinde işletmelerin iş modeli yeniliği, insan kaynakları gelişimi, iş yaratma, risk ve güvenlik yönetimi ile sosyal refah iyileştirme gibi sosyal sürdürülebilirlik işlevleri kazandığını; doğal bir sonuç olan ekonomik kazancın beraberinde daha yüksek maaş ve ekonomik eşitlik, sosyal denge ve daha iyi çalışma koşulları getirdiğini belirtmektedir. Endüstri 4.0 teknolojilerinin çalışanlar üzerindeki etkisi özelinde ise Margherita ve Braccini (2020), çalışanların yetkinlik ve sorumluluklarının arttığına vurgu yapmaktadır. Brozzi, Forti, Rauch ve Matt (2020) tarafindan Endüstri 4.0'ın sürdürülebilirlik üzerindeki etkisini ölçmek amacıyla yapılan anket çalışması sonucunda katılımcıların \%40'ının Endüstri 4.0 uygulamalarının fiziksel stresi azalttığ1, \%24,6’sının ise iş esnekliğini artırdığı fikrini desteklediği görülmüştür.

37 | P a g e

www.iiste.org 
AB Komisyonu, Endüstri 5.0'ı karakterize eden en önemli paradigmatik geçişlerden birini, odak noktasının teknoloji odaklı ilerlemeden tamamen insan merkezli bir yaklaşıma kayması olarak görmektedir. Endüstrinin sağlayacağı güvenli ve faydalı çalışma ortamı, insan haklarına saygı ve iş̧̧ilerin beceri gereklilikleri özellikle vurgulanmaktadır. Akıllı üretim çağını simgeleyen dördüncü sanayi devrimi böylece insan merkezli beşinci sanayi devrimine geçiş yapmaktadır (European Commission, 2021).

$\mathrm{AB}$ Komisyonu Endüstri 5.0 vizyonu ile sosyal boyuta verdiği önemi net bir şekilde ortaya koymaktadır. Bu çalışmasında yapay zekanın regülasyonu ile ilgili yayınlamış olduğu White Paper ve Avrupa Veri Stratejisi'ne değinerek dijital teknolojilerin sosyal etkisini vurgulamakta ve Endüstri 5.0'1 Toplum 5.0 ile ilişkilendirmektedir. AB Komisyonu; Toplum 5.0 ve Endüstri 5.0 kavramlarını, toplumun ve ekonominin yeni bir paradigmaya doğru köklü bir değişime işaret etmesi anlamında ilişkili olarak değerlendirmektedir. Toplum 5.0, ekonomik kalkınmayı sosyal ve çevresel sorunların çözümü ile dengelemeye çalışmaktadır (European Commission, 2021).

$\mathrm{Bu}$ çalışmalar dijital teknolojilerin sürdürülebilirlik ve sosyal boyut ile olan bağlantısını ve önemini net bir şekilde ortaya koymaktadır. Sonuç itibariyle; tablodaki mevcut dijital dönüşüm tanımlarında yer alan etkilere ve beklentilere insanı merkezine alan, dijital yetkinlikleri ve sosyal sürdürülebilirliği dahil eden yeni bir tanıma ihtiyaç duyulmaktadır.

Disselkamp ve Heinemann (2018) aşağıdaki tanımlamalarında "dijital ve sosyal dönüşümden" bahsetmektedirler. Bu çalışmadaki amaç ise, dijital dönüşümün çok yönlülüğünü göstermekle birlikte dönüşümün stratejik ve sosyal boyutunu kapsayan yeni bir "dijital dönüşüm” tanımını önermektir.

Disselkamp ve Heinemann'ın "dijital ve sosyal dönüşüm” tanımlaması, dijital yıkımların sadece klasik dijital konuları kapsamadığını aynı anda toplumsal ve sosyal alanları da etkilediğini vurgulamaktadır: "Sürekli gelişen dijital teknolojilere dayanan dijital dönüşüm, toplumun ve ekonominin devam eden değişim sürecidir. Bu dönüşümü̈n iki boyutu bulunmaktadir: İlki mevcut sistemlerin (teknolojiler, uygulamalar, metotlar, iş modelleri ve organizasyonlar) gelişimi ve optimizasyonudur. Aynı anda dijital dönüşüm yıkıcı sistem ve yapı dönüşümüne neden olmaktadır. Mevcut modellerin yerine yeni ve inovatif yaklaşımlar geçmektedir. Bu ylkımlar sadece klasik dijital konuları -BT veya süreçler gibikapsamamakta ayn anda toplumsal ve sosyal alanlar da etkilemektedir. Bu nedenle dijital ve sosyal dönüşümden bahsedilmektedir." (2018: 1).

\section{5. Önerilen Dijital Dönüşüm Tanımı}

Araştırma kapsamında ana kaynaklardan derlenen dijital dönüşüm tanımları; teknoloji, organizasyonel ve sosyal faktörler açısından değerlendirildiğinde ve globalleşen dünyadaki rekabet edebilirlik ile birlikte sosyal sürdürülebilirlik boyutu dahil edildiğinde dijital dönüşüm kavramına yeni bir anlam kazandırmanın önemi ortaya çıkmaktadır.

Dijital dönüşümün; insanı merkezine alan, insan yaşamını kolaylaştıran ve ona değer katan, yaşam kalitesini artıran özelliğine sürdürülebilirlik unsurunun da eklenmesi önemli bir gerekliliktir. "Gelecek nesillerin kendi ihtiyaçlarını karşılama yeteneğinden ödün vermeden bugünün ihtiyaçlarını karșılama" (WCED, 1987: 40) dijital dönüşümün sosyal boyutu için de vazgeçilmezdir. Dönüşüm sürecinin insan odaklı yaklaşımı, önerilen tanımda dijital yetkinlikler ve sosyal sürdürülebilirlik ile vurgulanmışıtır.

$\mathrm{Bu}$ araştırma kapsamında derlenen tanımlar incelendiğinde dijital dönüşümün beklentileri sektör, işletmeye veya departmana bağlı olarak farklılık gösterse de tüm bunları işletmelerin rekabet edebilirlik hedefi başlığı altında toplamanın mümkün olduğu görülmektedir. Sonuç itibariyle; yukarıda derlenen beklentilerin tek amacı, globalleşen ve dijital teknolojiler sayesinde birbiri ile bağlanan iş dünyasında rekabet edebilmektir. Dijital dönüşümün başarılı olması için stratejik bir amacının olması gerekmektedir. $\mathrm{Bu}$ nedenle dijital stratejilerinin odak noktası dijital teknolojilerin kullanımı ile işletmenin rekabet edebilirliğini korumak ve artırmaktır (Disselkamp ve Heinemann, 2018: 47).

Dijitalleşme ve ağ oluşumu sayesinde işletmeler hem maliyet liderliğini hem de fayda liderliğini üstlenerek, yeni iş modelleri oluştururken operasyonel mükemmelliği yeni müşteri deneyimleri ile bütünleştirebilme imkanına sahip olabilmektedir (Disselkamp ve Heinemann, 2018: 48). Dijital dönüşümün stratejik başarısı için önem taşıyan MIT Sloan Digital Business Modelin üç dijital stratejisi -müşteri deneyimi, operasyonel süreç ve iş modeli- bu araştırmada önerilen tanımda değerlendirilmiştir (aktaran Disselkamp ve Heinemann, 2018: 48).

Araştırma kapsamında ortaya konulan tüm açıklamalar doğrultusunda dijital dönüşüm için yeni bir

38 | P a g e

www.iiste.org 
tanım önerilmektedir. Önerilen bu tanım dijital dönüşüm çalışmalarının tek seferlik bir eylem olmadığını, sürdürülebilirliği esas alan ve köklü bir dönüşüm olduğunu da vurgulamaktadır:

"Dijital dönüşüm, sosyal sürdürülebilirliği sağlamak ve rekabet edebilirliği arttrrmak amacıyla dijital teknolojileri ve dijital yetkinlikleri kullanarak dijital stratejileri oluşturan operasyonel süreçlerin, müşteri deneyimlerinin ve iş modellerinin köklü ve ivmeli dönüşümüdür."

\section{Sonuc}

Dijital dönüşüm insanların öğrenme ve iletişim kurma yöntemlerini, birlikte yaşama ve birlikte çalışma alışkanlıklarını temelden değiştirerek dijital toplumu oluşturmaya başlamıştır. Dijital dönüşüm kapsamında kullanılan dijital teknolojiler insan hayatını kolaylaştıran ve yaşam kalitesini artıran sosyal etkilere neden olmaktadır. Dijital dönüşüm gelecekte yaşam kalitemizi artıracak yeni firsatlara öncülük edecektir.

$\mathrm{Bu}$ nedenle dijital dönüşümün insanı merkezine alarak sosyal boyutu göz önünde bulunduran sürdürülebilir yönetimi, gelecek nesiller ve işletmelerin gelecekteki varoluşları için stratejik önem taşımaktadır. Avrupa Birliği Komisyonu'nun da Endüstri 5.0 vizyonu ile esneklik dışında insana ve sürdürülebilirliğe odaklanması sosyal sürdürülebilirliğin dijital çağda daha çok önem kazanacağını göstermektedir.

Sürdürülebilirliğin üç boyutu arasında sosyal sürdürülebilirlik en az gelişen ve üstünde tartışılan olmuştur. Dijital dönüşümün sosyal sürdürülebilirlik ile olumlu bağlantısı olmasına rağmen bilimsel çalışmalarda yer alan dijital dönüşüm tanımlarında bu ilişkiye hiç değinilmediği gibi sosyal sürdürülebilirlik kavramı da hiç yer almamaktadır. Dijital dönüşüm teknolojilerinin toplumda yaygınlaşan sosyal etkileri ve sosyal sürdürülebilirliğin artan önemi nedeniyle bu araştırmada yeni bir dijital dönüşüm tanımı önerilmiştir. Önerilen tanım dijital dönüşümün işletmeler açısından çok boyutluluğunu da göz önünde bulundurmaktadır.

Dijital dönüşümün sürekli gelişen bir süreç olması nedeniyle, önerilen bu tanımın gelişmelere bağlı olarak zamanla uyarlanması hedeflenmektedir.

\section{Kaynakça}

A strong and positive link. (t.y.). Erişim adresi https://digitalaccessindex-sdg.gesi.org/a-strong-andpositive-link/

Anania, L., \& Passani, A. (2014). A Hitchiker 's Guide to Digital Social Innovation. Paper presented at the 20th Biennial Conference of the International Telecommunications Society (ITS): "The Net and the Internet - Emerging Markets and Policies", Rio de Janeiro, Brazil, 30th-03rd December, 2014.

Andriole, S. J. (2017). Five myths about digital transformation. MIT Sloan Management Review, 58(3), 20-22. https://doi.org/10.7551/mitpress/11633.003.0005

Ballet, J., Bazin, D., \& Mahieu, F. R. (2020). A policy framework for social sustainability: Social cohesion, equity and safety. Sustainable Development, 28(5), 1388-1394. https://doi. org/10.1002/sd.2092

Bañon Gomis, A. J., Guillén Parra, M., Hoffman, W. M., \& Mcnulty, R. E. (2011). Rethinking the Concept of Sustainability. Business and Society Review, 116(2), 171-191. https://doi.org/ $10.1111 / j .1467-8594.2011 .00381 . x$

Beier, G., Ullrich, A., Niehoff, S., Reißig, M., \& Habich, M. (2020, June 20). Industry 4.0: How it is defined from a sociotechnical perspective and how much sustainability it includes - A literature review. Journal of Cleaner Production. Elsevier Ltd. https://doi.org/ 10.1016/ j.jclepro.2020.120856 
Berghaus, S., \& Back, A. (2016). Stages in Digital Business Transformation: Results of an Empirical Maturity Study. Mediterranean Conference on Information Systems (MCIS), (Paper 22), 1-17. Erişim adresi http://aisel.aisnet.org/mcis2016\%0Ahttp://aisel.aisnet.org/mcis2016

Bloching, B., Leutiger, P., Oltmanns, T., Rossbach, C., Schlick, T., Remane, G., ... Shafranyuk, O. (2015). Die digitale Transformation der Industrie. Roland Berger Strategy Consultants GmbH $\&$ Bundesverband der Deutschen Industrie. https://bdi.eu/media/ presse/publikationen/ information-und-telekommunikation/Digitale_Transformation.pdf

Bloomberg, J. (2018, April 29). Digitization, Digitalization, And Digital Transformation: Confuse Them At Your Peril. Erişim adresi https://www.forbes.com/sites/ jasonbloomberg/ 2018/04/29/digitization-digitalization-and-digital-transformation-confuse-them-at-yourperil/?sh=e30030d2f2c7

Brozzi, R., Forti, D., Rauch, E., \& Matt, D. T. (2020). The advantages of industry 4.0 applications for sustainability: Results from a sample of manufacturing companies. Sustainability (Switzerland), 12(9). https://doi.org/10.3390/su12093647

Cangiano, S., Romano, Z., \& Loglio, M. (2017). The growth of digital social innovation in Europe. An Open Design approach to support innovation for the societal good. Design Journal, 20(sup1), S3546-S3559. https://doi.org/10.1080/14606925.2017.1352857

Demirkan, H., Spohrer, J. C., \& Welser, J. J. (2016, November 1). Digital Innovation and Strategic Transformation. IT Professional. IEEE Computer Society. https://doi.org/ 10.1109/MITP. 2016.115

Digitalization. (t.y.). Erişim adresi https://www.gartner.com/en/information-technology/ glossary/ digitalization

Disselkamp, M., \& Heinemann, S. (2018). Digital-Transformation-Management: Den digitalen Wandel erfolgreich umsetzen. Stuttgart: Schäffer-Poeschel Verlag.

Eizenberg, E., \& Jabareen, Y. (2017). Social sustainability: A new conceptual framework. Sustainability (Switzerland), 9(1). https://doi.org/10.3390/su9010068

Elkington, J. (2018, June 25). 25 Years Ago I Coined the Phrase “Triple Bottom Line.” Here's Why It's Time to Rethink It. Erişim adresi https://hbr.org/2018/06/25-years-ago-i-coined-the-phrasetriple-bottom-line-heres-why-im-giving-up-on-it

European Commission. (2021). Industry 5.0: Towards a sustainable, human-centric and resilient European industry. Erişim adresi https://msu.euramet.org/ current_calls/ documents/ EC_Industry5.0.pdf

Faludi, J. (2020). How to Create Social Value Through Digital Social Innovation? Unlocking the Potential of the Social Value Creation of Digital Start-Ups. Journal of Social Entrepreneurship. https://doi.org/10.1080/19420676.2020.1823871

Fenwick, T., \& Edwards, R. (2016). Exploring the impact of digital technologies on professional responsibilities and education. European Educational Research Journal, 15(1), 117-131. https://doi.org/10.1177/1474904115608387

Fitzgerald, M., Kruschwitz, N., Bonnet, D., \& Welch, M. (2013). Embracing Digital Technology: A New Strategic Imperative. MIT Sloan Management Review, 55(1), 1-13. Erişim adresi https://www.capgemini-consulting.com/SMR

40 | P a g e

www.iiste.org 
Ghobakhloo, M. (2020). Industry 4.0, digitization, and opportunities for sustainability. Journal of Cleaner Production. Elsevier Ltd. https://doi.org/10.1016/j.jclepro.2019.119869

Gimpel, H., \& Röglinger, M. (2015). Digital Transformation: Changes and Chances. Frauenhofer Institute for Applied Information Technology Fit. https://fim-rc.de/wp-content/ uploads/ 2020/02/Fraunhofer-Studie_Digitale-Transformation.pdf

Giovannoni, E., \& Fabietti, G. (2013). What is sustainability? A review of the concept and its applications. Integrated Reporting: Concepts and Cases that Redefine Corporate Accountability içinde (21-40). Springer International Publishing. https://doi.org/10.1007/978-3319-02168-3_2

Gregori, P., \& Holzmann, P. (2020). Digital sustainable entrepreneurship: A business model perspective on embedding digital technologies for social and environmental value creation. Journal of Cleaner Production, 272. https://doi.org/10.1016/j.jclepro.2020.122817

Grum, B., \& Kobal Grum, D. (2020). Concepts of social sustainability based on social infrastructure and quality of life. Facilities, 38(11-12), 783-800. https://doi.org/10.1108/F-042020-0042

Guo, H., Nativi, S., Liang, D., Craglia, M., Wang, L., Schade, S., ... Annoni, A. (2020). Big Earth Data science: an information framework for a sustainable planet. International Journal of Digital Earth, 13(7), 743-767. https://doi.org/10.1080/17538947.2020.1743785

Haffke, I., Kalgovas, B., \& Benlian, A. (2016). The role of the CIO and the CDO in an Organization's Digital Transformation. In 2016 International Conference on Information Systems (ICIS 2016). Association for Information Systems.

Hartl, E., \& Hess, T. (2017). The role of cultural values for digital transformation: Insights from a delphi study. In AMCIS 2017 - America's Conference on Information Systems: A Tradition of Innovation (Vol. 2017-August). Americas Conference on Information Systems.

Heilig, L., Schwarze, S., \& Voss, S. (2017). An Analysis of Digital Transformation in the History and Future of Modern Ports. In Proceedings of the 50th Hawaii International Conference on System Sciences (2017). Hawaii International Conference on System Sciences. https://doi.org/10.24251/hicss.2017.160

Henriette, E., Feki, M., \& Boughzala, I. (2016, September). Digital Transformation Challenges. In MCIS 2016 Proceedings (p. 33).

Hess, T., Benlian, A., Matt, C., \& Wiesböck, F. (2016). Options for formulating a digital transformation strategy. MIS Quarterly Executive, 15(2), 123-139. https://doi.org/ $10.4324 / 9780429286797-7$

Holzbaur, U. (2020). Nachhaltige Entwicklung: Das Weg in eine lebenswerte Zukunft. Springer. https://doi.org/10.1007/978-3-658-29991-0

i-scoop. (t.y.). Digital transformation: online guide to digital business transformation. Erişim adresi https://www.i-scoop.eu/digital-transformation/

Junge, A. L., \& Straube, F. (2020). Sustainable supply chains - Digital transformation technologies' impact on the social and environmental dimension. In Procedia Manufacturing (Vol. 43, pp. 736-742). Elsevier B.V. https://doi.org/10.1016/j.promfg.2020.02.110 
Kane, G. C. (2017). Digital Maturity, Not Digital Transformation. MIT Sloan Management Review, 3-7. Erişim adresi http://sloanreview.mit.edu/article/digital-maturity-not-digital-transformation/

Kuhlman, T., ve Farrington, J. (2010). What is sustainability? Sustainability, 2(11), 3436-3448. https://doi.org/10.3390/su2113436

KPMG. (2020). KPMG Digital Transformation Playbook - Digital Transformation in the Saudi Levant Cluster. Erişim adresi https://assets.kpmg/content/dam/kpmg/sa/pdf/2020/digitaltransformation-playbook.pdf

Leal Filho, W. (2000). Dealing with misconceptions on the concept of sustainability. International Journal of Sustainability in Higher Education, 1(1), 9-19. https://doi.org/ 10.1108/ 1467630010307066

Li, L., Su, F., Zhang, W., \& Mao, J. Y. (2018). Digital transformation by SME entrepreneurs: A capability perspective. In Information Systems Journal (Vol. 28, pp. 1129-1157). Blackwell Publishing Ltd. https://doi.org/10.1111/isj.12153

Liu, D. Y., Chen, S. W., \& Chou, T. C. (2011). Resource fit in digital transformation: Lessons learned from the CBC Bank global e-banking project. Management Decision, 49(10), 17281742. https://doi.org/10.1108/00251741111183852

Margherita, E. G., \& Braccini, A. M. (2020). Industry 4.0 Technologies in Flexible Manufacturing for Sustainable Organizational Value: Reflections from a Multiple Case Study of Italian Manufacturers. Information Systems Frontiers. https://doi.org/10.1007/s10796-020-10047-y

Mazzone, D. M. (2014). Digital or Death: Digital Transformation: The Only Choice for Business to Survive Smash and Conquer. Smashbox Consulting Inc.

Mergel, I., Edelmann, N., \& Haug, N. (2019). Defining digital transformation: Results from expert interviews. Government Information Quarterly, 36(4). https://doi.org/10.1016/j.giq.2019.06.002

Missimer, M., Robèrt, K. H., \& Broman, G. (2017a). A strategic approach to social sustainability Part 1: exploring the social system. Journal of Cleaner Production, 140, 32-41. https://doi.org/10.1016/j.jclepro.2016.03.170

Missimer, M., Robèrt, K. H., \& Broman, G. (2017b). A strategic approach to social sustainability Part 2: a principle-based definition. Journal of Cleaner Production, 140, 42-52. https://doi.org/10.1016/j.jclepro.2016.04.059

Naisbitt, J., Naisbitt, N., \& Philips, D. (1999). High Tech/High Touch: Technology and Our Search for Meaning. Broadway Books.

Nwankpa, J. K., \& Roumani, Y. (2016). IT capability and digital transformation: A firm performance perspective. In 2016 International Conference on Information Systems (ICIS 2016). Association for Information Systems.

Osburg, T. (2017). Sustainability in a Digital World Needs Trust. Sustainability in a Digital World: New Opportunities Through New Technologies içinde (3-19). Osburg, T., \& Lohrmann, C. Springer International Publishing AG.

Osburg, T., \& Lohrmann, C. (2017). Sustainability in a Digital World: New Opportunities Through New Technologies. Springer International Publishing AG. 
PwC. (2015). Digital Controlling - Digitale Transformation im Controlling. Erişim adresi https://www.pwc.de/de/digitale-transformation/assets/pwc-studie-digitale-transformation-imcontrolling.pdf

Reis, J., Amorim, M., Melão, N., \& Matos, P. (2018). Digital transformation: A literature review and guidelines for future research. In Advances in Intelligent Systems and Computing (Vol. 745, pp. 411-421). Springer Verlag. https://doi.org/10.1007/978-3-319-77703-0_41

Samuels, M. (2018, May 22). What is digital transformation? Everything you need to know about how technology is reshaping business. Erişim adresi https://www.zdnet.com/article/what-isdigital-transformation-everything-you-need-to-know-about-how-technology-is-reshaping/

Schuchmann, D., \& Seufert, S. (2015). Corporate Learning in Times of Digital Transformation: A Conceptual Framework and Service Portfolio for the Learning Function in Banking Organisations. International Journal of Advanced Corporate Learning (IJAC), 8(1), 31. https://doi.org/10.3991/ijac.v8i1.4440

Solis, B. (2017). The 2017 State of Digital Transformation. Are Companies Investing in Digital Strategies? Altimeter, (October), 1-38. Erişim adresi https://insights.prophet.com/state-digitaltransformation-2017

Stief, S. E., Eidhoff, A. T., \& Voeth, M. (2016). Transform to Succeed: An Empirical Analysis of Digital Transformation in Firms. World Academy of Science, Engineering and Technology, International Journal of Social, Behavioral, Educational, Economic, Business and Industrial Engineering, 10(6), 1550-1559.

Stolterman, E., \& Fors, A. K. (2004). Information Technology and the Good Life, Information Systems Research: Relevant Theory and Informed Practice. In Information Systems Research. IFIP International Federation for Information Processing (pp. 687-692).

Sürdürülebilir Kalkınma Amaçları Nelerdir? (t.y.). Sürdürülebilir Kalkınma Amaçları içinde. Erişim adresi https://www.tr.undp.org/content/turkey/tr/home/sustainable-development-goals.html

Tekic, Z., \& Koroteev, D. (2019). From disruptively digital to proudly analog: A holistic typology of digital transformation strategies. Business Horizons, 62(6), 683-693. https://doi.org/ 10.1016/j.bushor.2019.07.002

Unruh, G., \& Kiron, D. (2017, November 6). Digital Transformation on Purpose. Erişim adresi https://sloanreview.mit.edu/article/digital-transformation-on-purpose/

Vallance, S., Perkins, H. C., \& Dixon, J. E. (2011). What is social sustainability? A clarification of concepts. Geoforum, 42(3), 342-348. https://doi.org/10.1016/j.geoforum.2011.01.002

Vial, G. (2019, June 1). Understanding digital transformation: A review and a research agenda. Journal of Strategic Information Systems. Elsevier B.V. https://doi.org/ 10.1016/j.jsis.2019.01.003

Was bedeutet digitale Transformation für Unternehmen? (t.y.). Was ist digitale transformation? içinde. Erişim adresi https://smatechnologies.com/de/blog/digital-transformation-overview

Westerman, G., Calméjane, C., Bonnet, D., Ferraris, P., \& McAfee, A. (2011). Digital Transformation: A roadmap for billion-dollar organizations. MIT Center for Digital Business and Capgemini Consulting, 1, 1-68. 
World Commission on Environment and Development. (1987). Our Common Future. Oxford University Press.

Zaoui, F., \& Souissi, N. (2020). Roadmap for digital transformation: A literature review. In Procedia Computer Science (Vol. 175, pp. 621-628). Elsevier B.V. https://doi. org/10.1016/j.procs.2020.07.090 